\title{
Effect of RNA Interference on the Hepatitis C Virus Core Expression in HepG2/C3A Cells Using Genotype 4 Isolates from Saudi Patients
}

\author{
Medhat K. Shier1, Hebatallah H. Ali1, Mohammad S. El-Wetidy1, Mohammad M. Al-Qattan² \\ and Mohamed B. Al-Fageeh ${ }^{3}$ \\ ${ }^{1}$ College of Medicine Research Centre, King Saud University, Riyadh, Saudi Arabia \\ ${ }^{2}$ Department of Surgery, College of Medicine, King Saud University, Riyadh, Saudi Arabia \\ ${ }^{3}$ National Centre for Biotechnology, King Abdulaziz City for Science and Technology, Riyadh, Saudi Arabia
}

\begin{abstract}
Objective: To explore the effects of two different methodologies of RNA interference, namely small interfering RNA, and vector-based short hairpin RNA, on the expression levels of hepatitis C virus core RNA and protein of Saudi genotype 4 isolates.

Study Design: An experimental study.

Place and Duration of Study: Laboratories of the College of Medicine Research Center, King Saud University, Saudi Arabia, from January to December 2018.

Methodology: Hepatitis C virus core small interfering RNA molecule and short hairpin RNA vector were designed against core region. Viral RNA expression was tested by RT-PCR; whereas, core protein was tested by flow cytometry and immunofluorescence. Results were statistically analysed by Chi-square analysis to calculate the p-value.

Results: Both molecules caused a reduction in core RNA and protein expression in infected cells. The effect of 100-pmol of small interfering RNA was more evident. For the vector-based short hairpin RNA, inhibition of core RNA expression was quite evident after 96 hours $(p=0.007)$. The results of flow cytometry and immunofluorescence showed a decline in core protein expression. The most dramatic effect was observed with 100-pmol small interfering RNA treatment of cells for 24 and 48 hours, which resulted in $63.5 \%$ and $91.1 \%$ core RNA expression reduction, respectively.

Conclusion: RNA interference of hepatitis $\mathrm{C}$ virus core gene efficiently stopped viral replication and offer a promising therapeutic alternative against virus infection.
\end{abstract}

Key Words: Hepatitis C Virus, Genotype 4, HCV core expression, RNA interference, small interfering RNA, short hairpin RNA.

How to cite this article: Shier MK, Ali HH, El-Wetidy MS, Al-Qattan MM, Al-Fageeh MB. Effect of RNA interference on the hepatitis C virus core expression in HepG2/C3A cells using genotype 4 isolates from Saudi patients. J Coll Physicians Surg Pak 2019; 29(9):852-9.

\section{INTRODUCTION}

Hepatitis $\mathrm{C}$ virus (HCV) infection is a common international cause of chronic hepatitis, cirrhosis, and hepatocellular carcinoma possibly totaling up to 0.5 million deaths yearly. $\mathrm{HCV}$ is an enveloped virus with positive-sense single-stranded RNA (ssRNA). The HCV genome has 9600 nucleotides and an open reading frame flanked by 5' and 3' UTRs. ${ }^{1}$ Viral translation produces 3000 amino acid polyprotein precursor, which is subsequently cleaved into either viral structural or nonstructural (NS) proteins. ${ }^{2}$ Cellular peptidases cause the proteolytic digestion of viral polyproteins, finally producing 10 subunits including structural core $(\mathrm{C})$ protein. ${ }^{3}$ Based on

Correspondence to: Dr. Medhat K. Shier, College of Medicine Research Centre, King Saud University, P.O Box 2925 (74),

11461, Riyadh, Saudi Arabia

E-mail:mshier@ksu.edu.sa

Received: February 14, 2019; Revised: May 22, 2019;

Accepted: June 14, 2019 its genetic variability, HCV is classified into six genotypes $(1-6)$ and numerous subtypes epidemiologically linked to geographical zones and risk factors. ${ }^{4} \mathrm{HCV}$ Genotype 1 (G1) is the most common in the world, followed by G3, G2, G4, and G6.5 Until 2011, a typical treatment procedure includes a mixture of subcutaneous pegylated interferon (PEG-IFN) along with oral ribavirin (RBV), for 24 or 48 weeks. ${ }^{5}$ However, this treatment plan is unsuccessful in more than $40 \%$ of the patients. 6 Introduction of a new antiviral therapy with a specific target for HCV is a necessity to overcome the deficiencies of PEG-IFN/RBV therapy since there is also no effective vaccine until now. ${ }^{7}$

Therefore, there is a need for more efforts to develop other treatments. Aiming for HCV replication by RNA interference (RNAi) is a vital strategy for antiviral treatment. 8 This process proved its efficiency either as a therapeutic approach or as a molecular biology tool for the study of genetic roles. ${ }^{9}$ The current study aimed to investigate the inhibitory effects of RNAi on HCV G4 core gene expression in vitro. 
We concluded that targeting HCV G4 core gene, in a dose-dependent manner, inhibited efficiently mRNA and protein expression in HepG2/C3A cells, which suggested the RNA interference as a promising therapeutic approach against this specific genotype.

\section{METHODOLOGY}

The study was conducted at the Laboratories of the College of Medicine Research Centre, King Saud University, Riyadh, Saudi Arabia, from January to December 2018. Ten serum samples identified as positive to anti-HCV antibodies and negative to HBV markers and anti-HIV antibodies and with higher viral titers of minimum 300,000 copies $/ \mathrm{ml}$, were obtained and documented by the Pathology Department, College of Medicine, King Saud University, Riyadh, Kingdom of Saudi Arabia (KSA). The ethical approval was obtained from the Ethics Committee at the College of Medicine and King Khalid University Hospital, King Saud University, Riyadh, KSA (Ref. No. 18/0172/IRB) in compliance with the Helsinki Declaration. All samples were genotyped using sequence analysis method as described earlier. 10

The transformed HepG2/C3A cell line (ATCC, Manassas, VA, USA) was grown in EMEM culture medium (LONZA, Basel, Switzerland) enriched with $10 \%$ fetal bovine serum (FBS) and incubated at $37^{\circ} \mathrm{C}$ in a $5 \% \quad \mathrm{CO}_{2}$ incubator. For viral inoculation, cells were grown in $6 \mathrm{~cm}^{2}$ culture dishes to 50 - $60 \%$ confluency ( 1 × $10^{6}$ cells), washed twice with fetal bovine serum (FBS)-free medium. For each dish, $500 \mu \mathrm{l}$ of HCV-positive serum sample was added in FBS-free media and incubated for 90 minutes. After incubation, dishes were supplied with complete EMEM media containing FBS and the final viral concentration was (0.05 copies/cell). Cells were incubated at $37^{\circ} \mathrm{C}$ and $5 \% \mathrm{CO}_{2}$ for 24 hours then the culture medium was replaced and dishes were reincubated until detection or treatment with RNAi molecules.

HCV core RNAi molecules were designed through the online tool BLOCK-iT ${ }^{\mathrm{TM}}$ RNAi Designer. The sequences of the chemically synthesised siRNA molecule are sense strand 5' AAA CCA AAC GUA ACA CCA Att 3' and antisense strand 3' ttU UUG GUU UGC AUU GUG GUU 5' at position 308 - 312 (corresponding to Ref. Y11604) and were synthesised and purchased from Applied Biosystems, Foster City, CA, USA. For vector-based short hairpin RNA (shRNA), the sequences were as follows: the sense strand: 5' GAT CCA CCA AAC GTA ACA CCA ACC TTC AAG AGA GGT TGG TGT TAC GTT TGG TTT A3' and the anti-sense strand 3' GTG GTT TGC ATT GTG GTT GGAAGT TCT CTC CAA CCA CAA TGC AAA CCAAAT TCG A 5' and were synthesised and purchased from ATUM (formerly DNA2.0 ${ }^{\circledR}$ ), Menlo Park, CA, USA. The shRNA molecule was cloned into the
pSilencer 2.1-U6 neo siRNA Expression vector (Ambion, Austin, Texas USA) through DH5 $\alpha$ cloning system as described earlier. ${ }^{11}$ Either siRNA or shRNA vectors were transfected, directly, to HepG2/C3A cells using Lipofectamine RNAi MAX reagent (Invitrogen, San Diego, CA, USA). Negative control siRNA was designed with a similar nucleotide composition as the experimental siRNA (scrambled siRNA) despite it lacked significant sequence homology to any HCV or human sequences. The siRNA\#1-NC1 (Applied Biosystems, Foster City, CA, USA) was transfected in the cell, acting as a negative control to determine transfection efficiency.

RNAi effect on cell viability was tested via MTT assay. Cells were treated with different concentrations of either molecule for 24 hours and then incubated with $5 \mathrm{mg} / \mathrm{ml}$ of 3-(4,5-dimethylthiazol-2-yl)-2,5-diphenyltetrazolium bromide (Applied Biosystems, Foster City, CA, USA) for two hours. Violet crystals were formed which were further diluted with DMSO and color intensity was measured by a plate reader at $570 \mathrm{~nm}$.

Cells were grown up to $80 \%$ confluence for three days post-inoculation with HCV infected sera. Cells were transfected with either the synthetic siRNA molecules $(50,100$, or $200 \mathrm{pmol})$ or with $1 \mu \mathrm{g}$ of HCV core shRNA vector using Lipofectamine RNAi MAX reagent (Invitrogen, Carlsbad, CA, USA). For synthetic siRNA, total RNA was harvested after 24 and 48 hours with different concentrations. In shRNA, HCV core shRNA vector was transfected and total RNA was harvested after 24, 48 and 96 hours. The extraction was done using TRIAZOL reagent (Invitrogen, Carlsbad, CA, USA), according to the manufacturer's instructions.

RT-PCR was executed as described earlier. ${ }^{10}$ Briefly, $500 \mathrm{ng}$ of viral RNA was used for each reaction. The thermal conditions were as follows: $50^{\circ} \mathrm{C}$ for $30 \mathrm{~min}$ (reverse transcription); $94^{\circ} \mathrm{C}$ for $15 \mathrm{~min}, 40$ cycles of three steps at $94^{\circ} \mathrm{C}$ for $30 \mathrm{~s}$ (denaturation), $58^{\circ} \mathrm{C}$ for $30 \mathrm{~s}$ (annealing) and $72^{\circ} \mathrm{C}$ for $1 \mathrm{~min}$ (extension); and $72^{\circ} \mathrm{C}$ for $10 \mathrm{~min}$. PCR products were examined on agarose gel electrophoresis and photographed using the gel documentation system, GEL DOC XR (BioRad, Pennsylvania, USA).

For Immunofluorescence analysis of HCV core protein, infected cells were seeded at a density of $8 \times 10^{4}$ cells/well. After 24, 48 hours for synthetic siRNA and 24, 48, 96 hours for HCV core shRNA vector, detection was performed. Results analysis is based on the emission of green fluorescent resulted from excited FITC fluorochrome, which tags the HCV core antibody and measured by fluorescent microscope as described earlier. ${ }^{12}$ For examination of $\mathrm{HCV}$ core protein by flow cytometry, infected cells were treated with synthetic siRNA for 24 and 48 hours and then were used for intracellular staining and indirect flow cytometry. Infected and noninfected cells were collected where analysis was performed by FACS caliber flow cytometer. The results 
analysis depended on the amount of FITC labelling of cells that indicates the amount of viral core protein expression as described earlier. 12

Statistical package of Microsoft Excel software was used for statistical analysis in this study and Chi-test was utilised for analysis of our data. $\mathrm{P}<0.05$ indicated statistically significant difference.

\section{RESULTS}

The MTT assay results showed that RNAi molecule, at different concentrations, did not cause any toxic effect to HepG2/C3A cells compared to untreated control (Figure $1 \mathrm{~A}$ ). HCV replication indicated by core RNA expression was examined with RT-PCR and showed that there is a variation in amplification intensity when using the three different primer sets. Using HCV positive serum samples, the primer set that gave the strongest PCR signal was selected for further experiments (Figure 1B).

To measure the effects of siRNA on HCV G4 core RNA expression, different concentrations $(50,100$ and 200 pmol) were transfected for different time periods (24 and $48 \mathrm{hrs}$ ). Various experimental settings declined core RNA signals, investigated by semi-quantitative RT-PCR. The inhibitory result of the 100 -pmol concentration of siRNA was more evident than the other two concentrations, both at 24- and 48-hour post-transfection, in contrast to scrambled molecules that showed no inhibition in different conditions (Figure 1C and 1D).

$\mathrm{HCV}$ core shRNA insert was cloned to produce HCV core shRNA vector where the insert is transcriptionally controlled by U6 promoter. Our results showed that vector-based shRNA inhibition of HCV core RNA expression was quite evident after 96 hours $(p<0.01)$; whereas, treatment for 24 and 48 hours showed some decline; but these differences were not significant (Figures 1E and 1F).

Treatment of cells with different concentrations of $\mathrm{HCV}$ core siRNA (50 and 100 pmol) showed a decline in HCV core protein expression. There was no significant variation between different doses after 24 hours of treatment, but there was a greater decline with $100-\mathrm{pmol}$ treatment after 48 hours of treatment using immunofluorescence (Figure 2A). Cells transfected with $\mathrm{HCV}$ core shRNA vector showed a reduction in HCV core protein expression relative to $\mathrm{HCV}$-infected with no treatment with the most prominent effect occurred after 96 hours post-transfection (Figure 2B). Flow cytometry analysis indicated that HCV core siRNA treatment of the cells inhibited core protein expression compared to the non-inhibitory effect of scrambled siRNA molecules (Figures $3 \mathrm{~A}$ and $3 \mathrm{~B}$ ). The most dramatic effect was observed with the 100 pmol siRNA treatment of cells for 48 hours $(91.1 \%$ decline), followed by the 24 hours treatment $(63.5 \%$ decline) with the same dose (Figures $3 B$ and $3 C)$.

\section{DISCUSSION}

$\mathrm{HCV}$ is one of the leading causes of chronic hepatic disease, and affects more than 185 million people globally. Currently, there is no vaccine that could prevent viral infection, due to the high rate of strain disparity. ${ }^{13}$ Though viral infections can be partly eradicated by the novel treatments of direct-acting antiviral (DAA) medications, the great specificity of DAAs against their viral regions might result in the appearance of resistance against treatment, besides the very high cost/benefit ratio of these agents. Therefore, introducing a novel treatment for HCV is a fundamental community health aim. With many clinical trials until now, gene treatment has progressed from a vision to clinical certainty. Several studies have been conducted to examine HCV replication in vitro through infecting different hepatocytes by HCV-positive serum to simulate HCV biology. ${ }^{14}$ In this study, HepG2/C3A cells were infected with native HCV derived from patient's serum.

RNAi strategy is extensively used as a tool for analysis of gene function, as it can utilise a degradation consequence on target gene mRNA with high sequence specificity without initiating an interferon response. It denotes a piece of thrilling new equipment with therapeutic uses for the treatment of several diseases, containing viral infections. RNAi is a promising treatment approach for viral infection because HCV has a single positive-stranded RNA molecule which replicates in the cytosol.15 Typically, there are three different forms of frequently used RNAi molecules: siRNA, shRNA, or microRNA (miRNA). siRNA are dsRNA molecules of about 19-23 base pair nucleotides, able to achieve sitespecific cleavage and destruction of the aimed mRNA. ${ }^{17}$ shRNAs contains two complimentary 19-22 bp RNA sequences connected by a short loop of $4-11$ nucleotides. Those RNAs are produced inside the cell by DNA vector-mediated assembly. ${ }^{11}$

The encoding region of HCV core does not show high variation rate; where nucleotides and the corresponding amino acids sequence, among various strains of $\mathrm{HCV}$, indicate a homology of $81-88 \%$ and $96 \%$, respectively. 16 The core protein is a much-conserved basic protein, which makes the chief element of HCV nucleocapsid. Core protein has multiple tasks including structural protein of HCV nucleocapsid, influencing lipid metabolism, apoptosis, and immune response. Despite the importance of HCV core region, no previous antiviral agent was designed against this particular protein. ${ }^{13}$ To competently inhibit core gene expression in vitro, two experimental designs were used; namely, chemically synthesised and vector-based core shRNA molecules. The chemically synthesised siRNA on HCV-4 core, with increasing concentrations after 24 and 48 hours, was used to measure its effects. All settings inhibited HCV core RNA expression. The treatment of transfected cells with a dose of 100 pmol of siRNA for 24 and 48 hours 


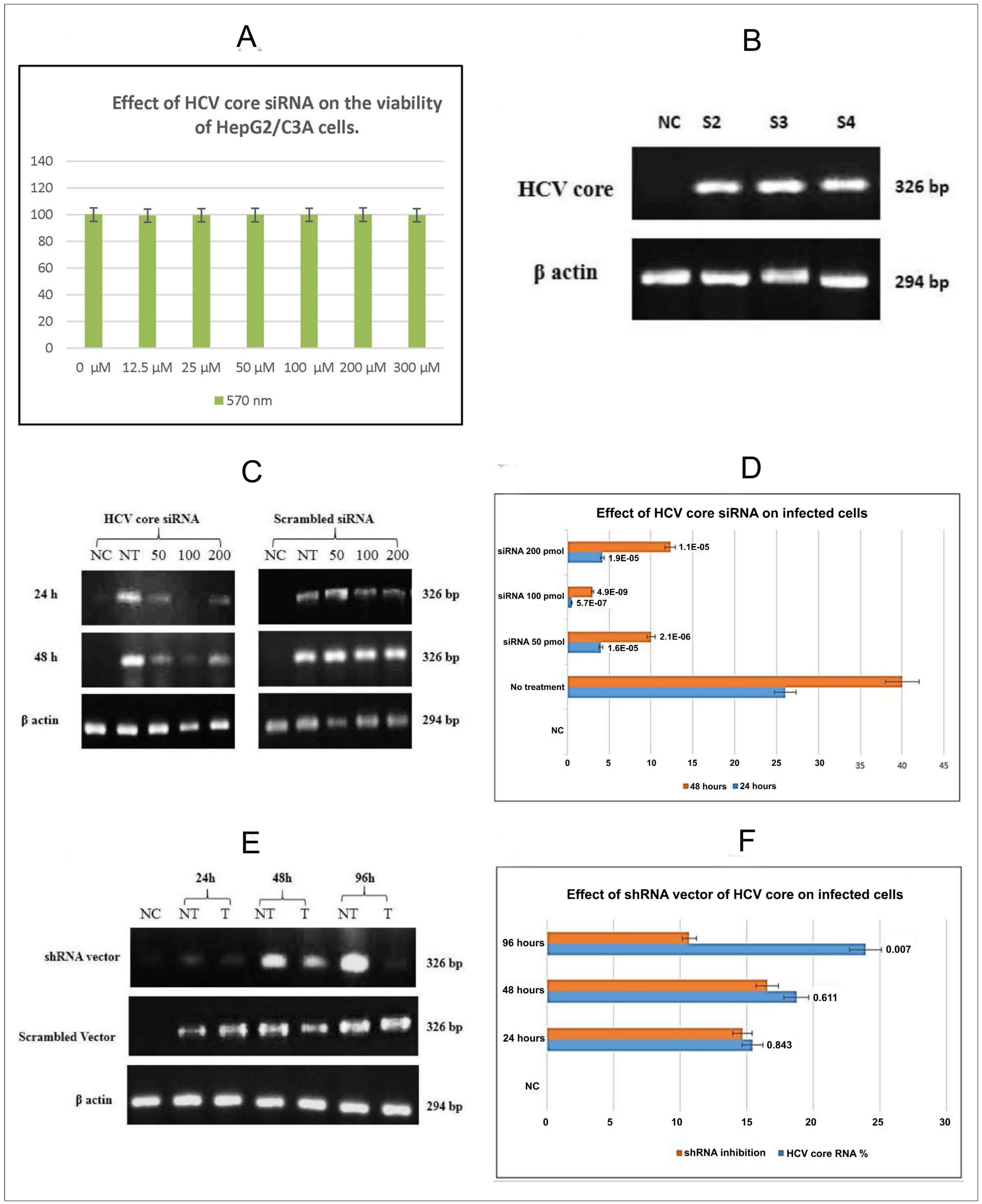

Figure 1: (A) MTT assay for cytotoxicity validation of siRNA molecule. (B) PCR results of one HCV negative serum (NC, S1) plus three positive sera (S2, S3 and S4) by three different primer sets to produce $326 \mathrm{bp}$ amplicon of HCV genotype 4 core. (C) Amplification of HCV core region after treatment with chemically synthetised core siRNA molecules by 50,100 and 200 pmol for $24 \mathrm{~h}$ and $48 \mathrm{~h}$. (D) Bar chart and statistical analysis of RT-PCR results of chemically synthetised core siRNA molecules treatment. (E) Amplification of HCV core region after treatment with vector-based core shRNA molecules by $1 \mu \mathrm{g}$ for $24 \mathrm{~h}, 48 \mathrm{~h}$, and $96 \mathrm{~h}$. (F) Bar chart and statistical analysis of RT-PCR results of vector-based core shRNA molecules treatment. 


\section{(A) Effect of HCV core chemically synthetized siRNA molecule on HCV infected cells:}
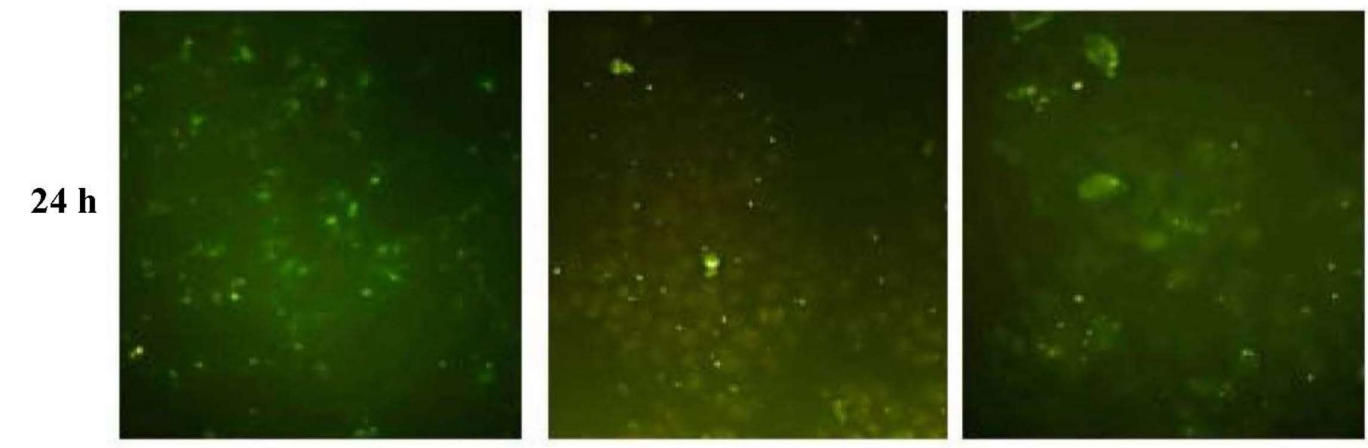

$48 \mathrm{~h}$

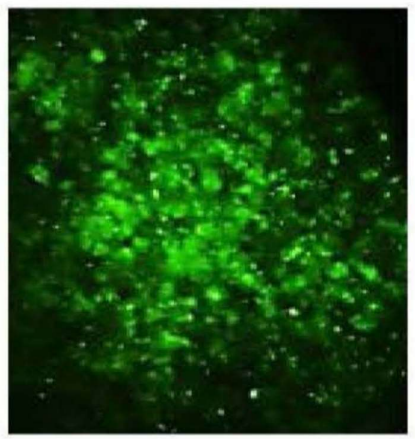

0 pmol

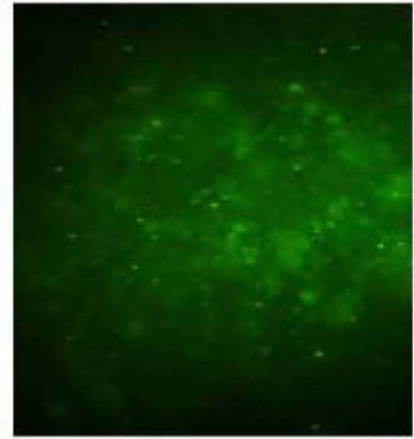

50 pmol

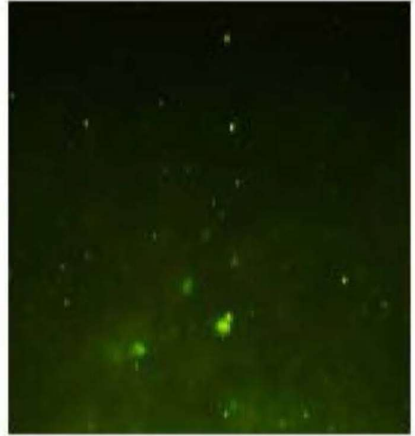

100 pmol

(B) Effect of HCV core shRNA vector molecule on HCV infected cells:
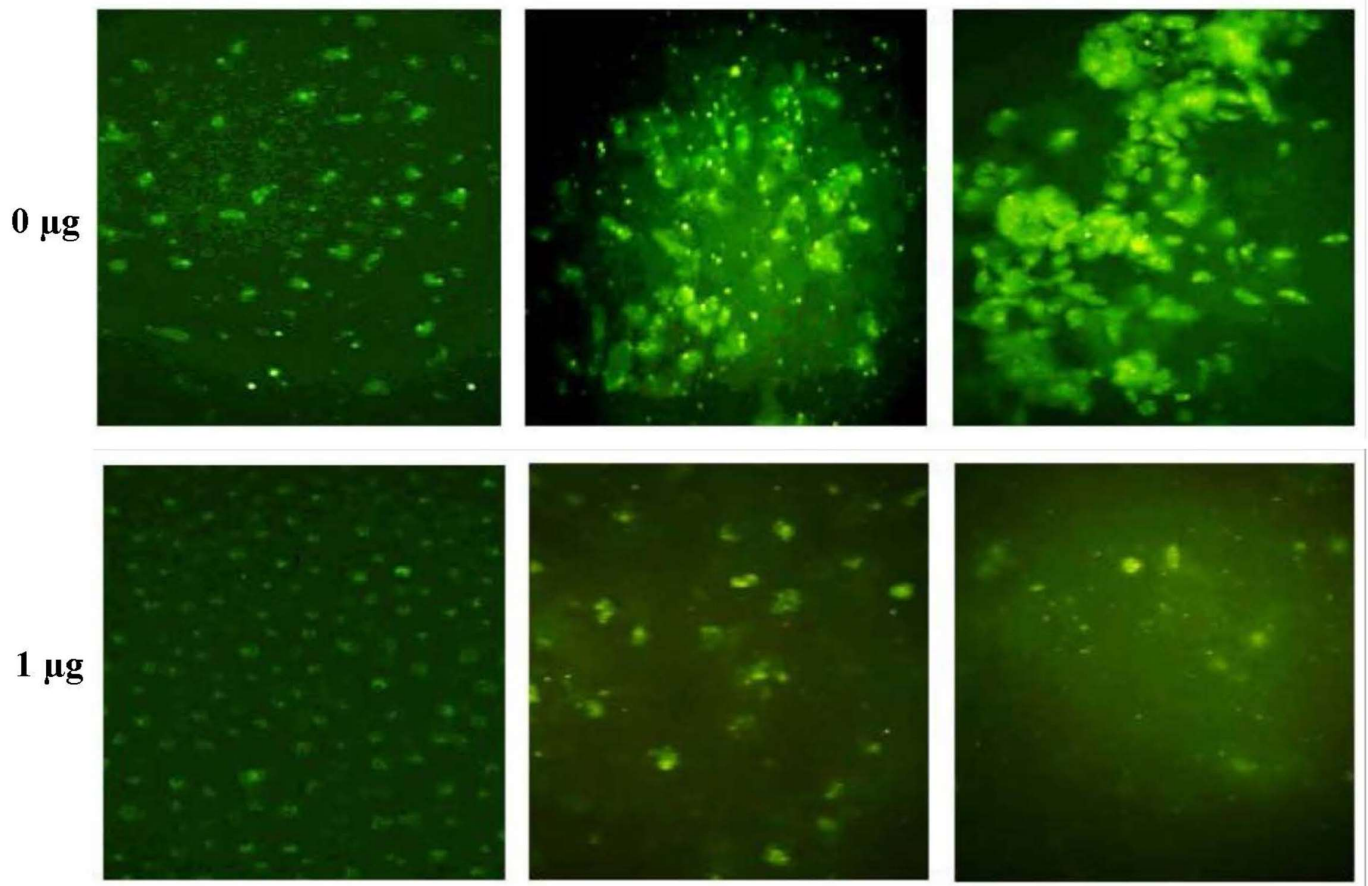

$24 \mathrm{~h}$

$48 \mathrm{~h}$

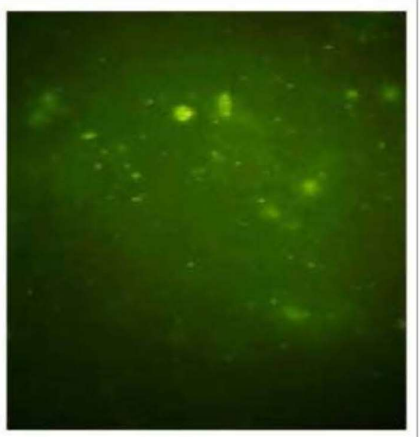

$96 \mathrm{~h}$

Figure 2: (A) HCV infected HepG2/C3A cells were treated with three doses of core siRNA (50, 100 and 200 pmol) and HCV core protein expression was tested with immunofluorescence $24 \mathrm{~h}$ and $48 \mathrm{~h}$ post-treatment using HCV core specific primary antibody. Results from negative control (NC), non-treated (NT) [10 $\mathrm{x}$ ] and the three doses [40x] were detected by fluorescent microscope blue excitation filter of FITC at 480/510 (Ex/Em). (B) HCV infected HepG2/C3A cells were treated with vector-based core shRNA $(1 \mu \mathrm{g})$ and $\mathrm{HCV}$ core protein expression was tested with immunofluorescence 24,48 and 96 hours post-treatment using $\mathrm{HCV}$ core specific primary antibody. Results from negative control (NC), non-treated (NT) [10 x] and the three doses [40x] were detected by fluorescent microscope blue excitation filter of FITC at 480/510 (Ex/Em). 


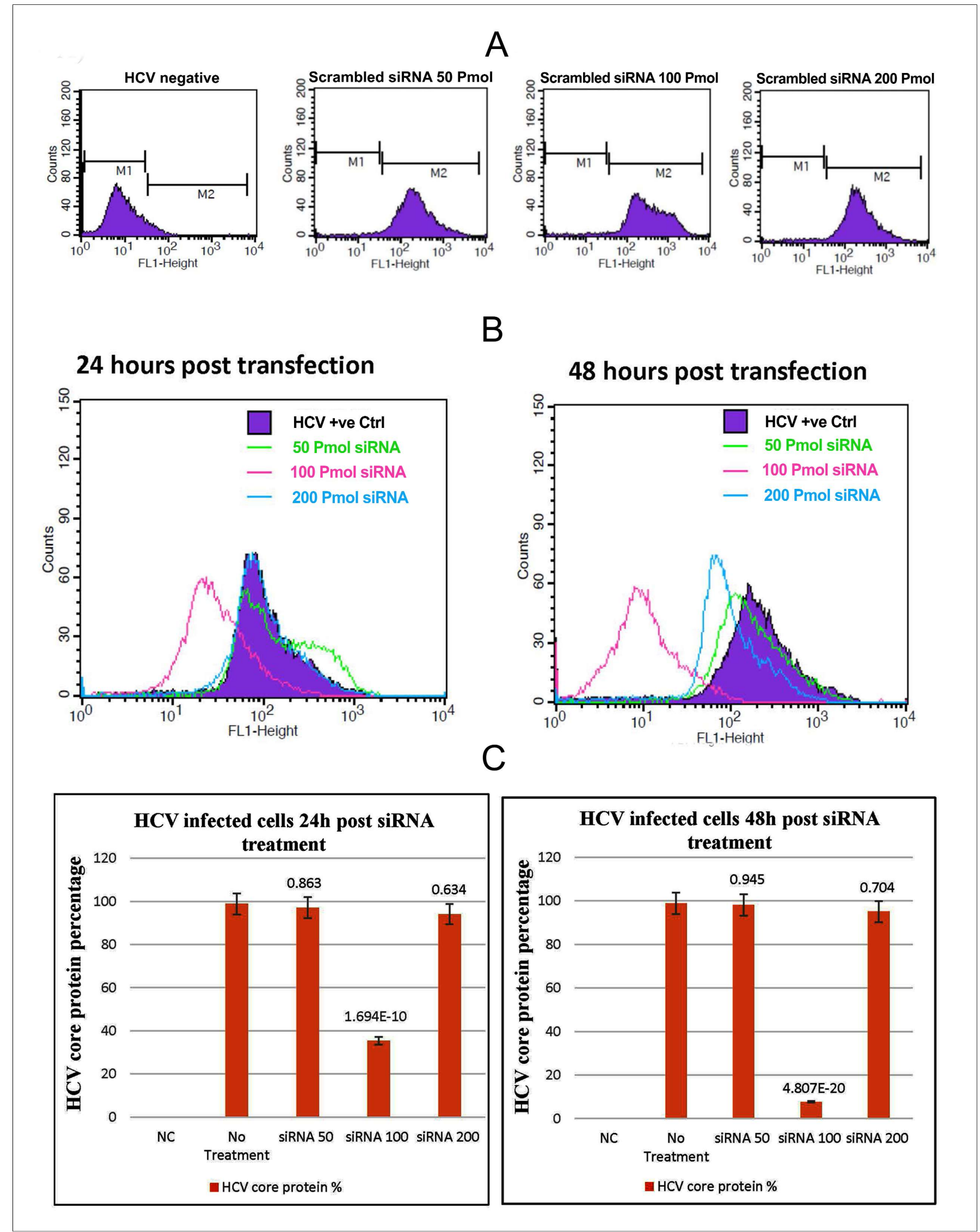

Figure 3: (A) Histogram of negative control (NC) and scrambled siRNA. (B) Histogram of HCV positive non-treated and siRNA treated cells at 24h and 48h. (C) Inhibition percentage of $\mathrm{HCV}$ core protein expression for all conditions versus negative control (NC). P-values are shown. 
caused a decline in HCV core RNA levels by $98 \%$ and $92.5 \%$, respectively. The main benefit of using synthesised siRNAs is that reaching the nucleus is not essential to exert its effects. However, adjustments are required to increase their stability, resulting in a partial loss of siRNA function. ${ }^{17}$

Vector-based intracellular transport of shRNA offered, another policy, that permits constant manufacture of shRNA besides allowing lasting eradication of viral gene expression. Our results have shown that the shRNA inhibited HCV-4 core RNA expression was quite evident after 96 hours ( $30 \%$ decline), compared to the effect after 48 hours $(17 \%)$. When shRNA expression plasmids are used, reaching the nucleus of cells is required. The resultant molecules are then transported to the cytoplasm and are incorporated into the RISC for activity. 18 Treatment of cells with different concentrations of HCV core siRNA showed a decline in HCV core protein expression levels. The immunofluorescent signal showed a higher decline with 100-pmol treatment after 48 hours of treatment. Cells transfected with HCV core shRNA vector showed a decrease in HCV core protein expression relative to $\mathrm{HCV}$-infected with no treatment with the most prominent effect occurred after 96 hours post-transfection.

Flow cytometric analysis indicated that HCV core siRNA treatment inhibited core protein expression. The most dramatic effect was observed with the 100 pmol siRNA treatment for 48 hours (91.1\% inhibition), compared to the decline after treatment with the same dose for 24 hours (63.5\% inhibition). Previous studies have revealed that HCV core siRNA declined protein and RNA expression. In two separate studies, results showed that siRNA against core gene of HCV $1 a$ and $1 b$ genotype downregulated mRNA and protein expression. 19 The gene quieting properties of siRNA is temporary and is only operative for 3 - 7 days before it disappears spontaneously. ${ }^{20}$ Therefore, there is a slim chance of unwanted manifestations, not like with other medications counting ribavirin and interferon. HCV G4 patients treated with DAA, especially the combination of sofosbuvir and daclatasvir or Ledipasvir for 12-24 weeks, showed dramatic response rate. However, the older age patients or those with cirrhosis, Child-Pugh class $\mathrm{B}$, or thrombocytopenia experienced limited or no response. ${ }^{21}$ RNAi effect against HCV replication has emerged very early at 24 hours post siRNA transfection. A previous study proposed that siRNA affecting HCV-3a core could compromise viral replication and indicate an effective therapeutic option for HCV infection.

The therapeutic applications of siRNA require many modifications in order to increase its stability, which may include the terminal phosphorothioate linkages, 2'-Omethyl and/or 2'-F-nucleotides. Additional challenge is the excessive silencing in non-relevant organs and tissues of the target, especially in non-disease relevant organs and tissues. Consequently, the targeted delivery of siRNA should increase the specificity which further enhances its efficacy and decreases the side effects. ${ }^{22}$ Recently, the US Food and Drug Administration has approved the first RNAi-based agent for neurodegenerative diseases affecting the central nervous system. The difficulties of RNAi delivery and inability to monitor activity, and specificity remain possible challenges. However, the therapeutic regimens of the new agent exhibited significant improvements. ${ }^{23}$

Continuous treatment with one RNAi molecule could encourage the appearance of several point mutations located inside the specific viral region. 24 To overcome developing viral mutations, multiple RNAi molecules aiming at multiple regions of the HCV genome is recommended, in addition to siRNAs against cellular proteins involved in HCV replication. The value of siRNA as a therapy against HCV infection will depend on establishing effective delivery systems that achieve a long-lasting RNAi activity. ${ }^{25}$

\section{CONCLUSION}

The competence of siRNA in hindering HCV G4 replication in cells suggests that RNAi could play an essential part in viral eradication during HCV G4 infection; and further experimental work is required for finding the best tools for delivering siRNA molecules into liver cells in vivo.

\section{FUNDING:}

This research was funded by the College of Medicine Research Center, Deanship of Scientific Research, King Saud University, Riyadh, Saudi Arabia.

\section{ETHICAL APPROVAL:}

Ethical approval was obtained from the Ethics Committee at the College of Medicine and King Khalid University Hospital, King Saud University, Riyadh, KSA (Ref. No. 18/0172/IRB) in compliance with the Helsinki Declaration.

\section{CONFLICT OF INTEREST:}

Authors declared no conflict of interest.

\section{AUTHORS' CONTRIBUTION:}

MKS: Concepts, design, definition of intellectual content, data acquisition, data analysis, manuscript preparation, manuscript editing, and manuscript review.

HHA: Design, literature research, experimental studies, data acquisition, manuscript preparation, manuscript editing, and manuscript review.

MSEW: Design, literature research, experimental studies, data analysis, statistical analysis, manuscript preparation, manuscript editing, and manuscript review.

MMAQ: Definition of intellectual content, manuscript editing, manuscript review, and guarantor. 
MBAF: Definition of intellectual content, manuscript editing, manuscript review.

\section{REFERENCES}

1. Morozov VA, Lagaye S. Hepatitis C virus: Morphogenesis, infection and therapy. World J Hepatol 2018; 10:186-212.

2. Tsukiyama-Kohara K, Kohara M. Hepatitis C virus: Viral quasispecies and genotypes. Int J Mol Sci 2017; 19:23.

3. Boukadida C, Fritz M, Blumen B, Fogeron ML, Penin F, Martin A. NS2 proteases from hepatitis $C$ virus and related hepaciviruses share composite active sites and previously unrecognized intrinsic proteolytic activities. PLoS Pathog 2018; 14: e1006863.

4. Simmonds P. The origin of hepatitis C virus. Curr Top Microbiol Immunol 2013; 369:1-15.

5. McEwan P, Ward T, Webster S, Kalsekar A, Brenner M, Yuan Y. Modeling the cost-effectiveness of the all oral, direct-acting antiviral regimen daclatasvir plus sofosbuvir in patients coinfected with hepatitis $\mathrm{C}$ virus (HCV) and HIV. Value Health 2015; 18:A628.

6. Pawlotsky JM. Therapy: Avoiding treatment failures associated with HCV resistance. Nat Rev Gastroenterol Hepatol 2015; 12:673-4.

7. Fauvelle C, Colpitts CC, Keck ZY, Pierce BG, Foung SK, Baumert TF. Hepatitis $C$ virus vaccine candidates inducing protective neutralizing antibodies. Expert Rev Vaccines 2016; 15:1535-44.

8. Bobbin ML, Rossi JJ. RNA interference (RNAi)-based therapeutics: Delivering on the promise? Annu Rev Pharmacol Toxicol 2016; 56:103-22.

9. Shier MK, lles JC, El-Wetidy MS, Ali HH, Al Qattan MM. Molecular characterization and epidemic history of hepatitis $C$ virus using core sequences of isolates from central province, Saudi Arabia. PLoS One 2017; 12:e0184163.

10. Shier MK, El-Wetidy MS, Ali HH, Al-Qattan MM. Hepatitis C virus genotype 4 replication in the hepatocellular carcinoma cell line HepG2/C3A. Saudi J Gastroenterol 2016; 22:240-8.

11. Chakraborty C, Sharma AR, Sharma G, Doss CGP, Lee SS. Therapeutic miRNA and siRNA: Moving from bench to clinic as next generation medicine. Mol Ther Nucleic Acids 2017; 8: 132-43.
12. Jiang XH, Xie YT, Cai YP, Ren J, Ma T. Effects of hepatitis C virus core protein and nonstructural protein $4 \mathrm{~B}$ on the Wnt/ $\beta$-catenin pathway. BMC Microbiol 2017; 17:124.

13. Ely $A$, Arbuthnot $P$. Differing prospects for the future of using gene therapy to treat infections with hepatitis $B$ virus and hepatitis C virus. Discov Med 2015; 20:137-43.

14. Bofill-De Ros X, Gu S. Guidelines for the optimal design of miRNA-based shRNAs. Methods 2016; 103:157-66.

15. Echeverría N, Moratorio G, Cristina J, Moreno P. Hepatitis C virus genetic variability and evolution. World J Hepatol 2015; 7:831-45.

16. Mirnurollahi SM, Bolhassani A, Irani S, Davoudi N. Expression and purification of $\mathrm{HCV}$ core and core-E1E2 proteins in different bacterial strains. Iran J Biotechnol 2015; 13:57-62.

17. Popescu Cl, Riva L, Vlaicu O, Farhat R, Rouillé Y, Dubuisson J. Hepatitis C virus life cycle and lipid metabolism. Biology 2014; 3:892-921.

18. Carneiro B, Braga AC, Batista MN, Harris M, Rahal P. Evaluation of canonical siRNA and Dicer substrate RNA for inhibition of hepatitis $C$ virus genome replication: A comparative study. PLOS One 2015; 10:e0117742.

19. Unniyampurath $U$, Pilankatta $R$, Krishnan MN. RNA interference in the age of CRISPR: Will CRISPR interfere with RNAi? Int J Mol Sci 2016; 17:291.

20. Mandal A, Ganta KK, Chaubey B. Combinations of siRNAs against La Autoantigen with NS5B or hVAP-A Have Additive Effect on Inhibition of HCV Replication. Hepat Res Treat 2016; 2016:9671031.

21. Ahmed OA, Elsebaey MA, Fouad MHA, Elashry H, Elshafie Al, Elhadidy $\mathrm{AA}$, et al. Outcomes and predictors of treatment response with sofosbuvir plus daclatasvir with or without ribavirin in Egyptian patients with genotype 4 hepatitis $C$ virus infection. Infect Drug Resist 2018; 11:441-5.

22. Lorenzer C, Dirin M, Winkler AM, Baumann V, Winkler J. Going beyond the liver: Progress and challenges of targeted delivery of siRNA therapeutics. J Control Release 2015; 203:1-15.

23. Kristen AV, Ajroud-Driss S, Conceição I, Gorevic P, Kyriakides T, Obici L. Patisiran, an RNAi therapeutic for the treatment of hereditary transthyretin-mediated amyloidosis. Neurodegener Dis Manag 2019; 9:5-23.

24. Youssef SS, Elemeery MN, Eldein SS, Ghareeb DA. Silencing HCV replication in its reservoir. Maced J Med Sci 2018; 6:1965-71.

25. Sarett SM, Nelson CE, Duvall CL. Technologies for controlled, local delivery of siRNA. J Control Release 2015; 218:94-113. 